\title{
EL ISLAM EN LOS DIALOGI DE PEDRO ALFONSO
}

\author{
Alfredo Ballestín \\ Doctor en Historia
}

\begin{abstract}
RESUMEN
Pedro Alfonso es uno de los personajes más importantes de la España Medieval. Sabio judío educado bajo el Islam y converso al Cristianismo, le hace ser conocedor de todo el bagaje religioso, científico y cultural, de las tres culturas monoteístas semíticas que durante siglos coexisten en la España Medieval, y que Pedro Alfonso transmitirá a Europa. Presentamos la traducción española del capítulo quinto de la obra Diálogos contra los judíos, en el que refuta con dureza la religión islámica.
\end{abstract}

Palabras clave: Pedro Alfonso, Islam, Judaísmo

\begin{abstract}
ASTRACT:
Pedro Alfonso is one of the most important persons in Medieval Europe. A wise Jew, educated under Islam and converted to Christianity, he is acquainted with all the religious, scientific and cultural background of the three monotheist semitic cultures that coexist in Medieval Spain along the centuries and that Pedro Alfonso will transmit in Europe. We present the Spanish translation of chapter fifth of the work Dialogues Against Jews, in which he strongly rejects the Islamic religion.
\end{abstract}

Key words: Pedro Alfonso, Islam, Judaism

\section{TITULO V. SOBRE LA LEY DE LOS SARRACENOS QUE HA DE DESTRUIRSE Y SOBRE LA NECEDAD DE SUS OPINIONES QUE HA DE REBATIRSE*}

MOISES:Hasta aquí, cuán vacía e inconstante sea en todo la fe judaica, y cuán irracional e ingrata resulta a Dios su práctica, $o$, por qué te has apartado de su fe, me lo expusiste y probaste con razones muy evidentes, y me mostraste en cuán gran error he permanecido hasta ahora. Pero ya que has abandonado la fe paterna, me admiro por qué has elegido la fe de los cristianos y no ya la de los sarracenos con los que siempre has vivido y te has educado. $\mathrm{Me}$ agradaría que, del mismo modo que acerca de la fe judía, también de esta secta poder deducir impedimentos, para que igual que hiciste con la nuestra también de ésta me muestres las razones con las que pueda ser destruida. Ya que siempre, como dije, has vivido y te has educado con ellos, leíste sus libros y entiendes su lengua, poniéndome ahora en lugar de ellos hu-

* El capítulo forma parte de la primera traducción completa al castellano del texto latino de los Dialogi, contenido en la edición de MIGNE (1899), teniéndose, además, en cuenta la edición de MIETH (1982), y otras obras fragmentarias dispersas. Cfr. BALLESTIN, A., El Dialogus contra iudaeos de Pedro Alfonso. Traducción y notas críticas. Su inserción en la tradición polémica judeo-cristiana. Prensas Universitarias de la Universidad de Zaragoza, Zaragoza, 2002. 
bieras debido elegir a esta por delante de las otras, ya que consta que es más honesta y soportable que las demás. Puesto que la Ley es ciertamente muy generosa en sus mandatos sobre los goces de la vida presente, en lo cual se manifiesta que era máxima la predilección divina hacia ellos, e igualmente a sus seguidores les promete a cambio gozos inefables. Si buscas, sin duda, la raíz de esta Ley, la encontrarás basada en el fundamento de una razón inconmovible. Por este motivo, Dios los amó y no quiso cargarlos con muchos mandatos, sino que tuvo consideración, de ello, es decir de que Dios los amó y que no quiso cargarlos con muchos mandatos, sino que tuvo consideración, es señal el que les ordenara que oraran tan sólo cinco veces al día, que siempre antes de orar tengan un aseo perfecto; las nalgas, las partes sexuales, manos, brazos, cara, boca, nariz, oídos, ojos, cabellos, con toda pulcritud, por último se lavan los pies. Hecho esto, proclaman públicamente su confianza en el único Dios, que no tiene igual o parecido y que Mahoma es su Profeta. Al año ayunan un mes entero. Al ayunar comen por la noche, de día se abstienen, de manera que desde la hora del día en la cual se pueda distinguir por la vista el hilo negro del blanco hasta la caída del sol, nadie se atreve a comer, beber o mancharse en el trato con la esposa. Pero después de la caída del sol, hasta el crepúsculo del día siguiente, siempre se les permite usar comida y bebida, y de las propias esposas, en la medida como cada uno quiera. Pero si está aquejado de una enfermedad o en camino, mientras dure la enfermedad o el camino a él le es permitido ${ }^{1}$ comer y usar cualquier cosa, pero de tal manera que lo que cumplió en menor medida por la necesidad de la enfermedad o del camino lo compense luego cuando le sea posible. Se ordena a todos que una vez al año, para reconocimiento, vayan a visitar la casa de Dios, que está en la Meca y allí hacer oración y dar una vuelta alrededor de la casa y revestidos con mantos sin costura, y lanzar piedras, tal como ordena la Ley, es decir, hacia atrás por entre las piernas para lapidar al diablo. Dicen que esta casa Adán, al ser desterrado del paraíso, la había levantado para el Señor, y que hasta la llegada de Abraham todos sus hijos la habían tenido como lugar de oración. Abrahán, fiel siervo de Dios, la robusteció, renovó y en ella hizo votos al Señor y ofreció sacrificios y después de su muerte la dejó a su hijo Ilamado Ismael. Y permaneció como casa de oración para él y todos sus hijos por muchos años, hasta que nació Mahoma. Nacido éste, Dios la prometió para él y para todas sus generaciones como hereditaria, tal como cuentan. Además, sus Profetas ordenan robar, hacer prisioneros, matar, perseguir de cualquier guisa y eliminar a los adversarios de Dios, a no ser que quieran arrepentirse y convertirse a su fe, o paguen el dinero impuesto a la esclavitud. Para ellos cualquier carne es idónea para alimentarse, salvo la carne y sangre del cerdo así como la de animales muertos. Rechazan todo lo que no esté consagrado sino en el nombre Dios. Además de esto se les permite tener al mismo tiempo cuatro mujeres legítimas, y si alguna es repudiada pueden tomar otra, y así de manera que no exceda el número de cuatro. En el repudio se observa esto, de modo que se les permite ${ }^{2}$ repudiar a cualquiera por tercera vez y volver a acogerla de nuevo. Compradas y esclavas se les permite tener cuantas quieran pero tendrán libre potestad para venderlas y adquirirlas de nuevo, sin embargo una vez que ha sido preñada de ningún modo pueden encadenarla al yugo de la esclavitud de otro. Se les concede tener mujeres de la propia parentela para que crezca el parentesco sanguíneo y se fortalezca entre ellos el vínculo de la amistad. Sobre las posesiones que han de reclamarse, las Leyes entre ellos son iguales que entre los hebreos, como lo sabes muy bien, de manera que el solicitante lo comprueba con testigos, y el que lo niega se purifica con juramento. Como testigos no aceptan sino a los muy idóneos y a personas probadas, y a los que se les puede creer sin juramento. En algunos otros puntos guardan la costumbre de la Ley de Moisés, de manera que quien ha derramado sangre humana sufre el mismo castigo (Gn19) y quien es sorprendido en adulterio, se le lapida junto con la adúltera (Lev20). Pero quien fornique con cualquier otra, será

1 «es permitido» conceditur; < PL 597 D 14.

2 «permite» liceat; liccat PL $598 \mathrm{C} 1$. 
sometido a ochenta azotes. Este es el castigo que se impone al robo: que en la primera y segunda ocasión sufra ochenta azotes, en la tercera pierda una mano, en la cuarta un pie, y quien arranque un miembro a cualquiera, lo redima con un precio digno. Todos estos preceptos han sido propuestos por Dios, para que una facultad muy amplia de obrar no trajere enseguida la ruina de todos. Se manda abstenerse siempre del vino, porque es estímulo y origen de todo pecado. Estos son los preceptos más importantes de la Ley, porque sería largo detenerse en cada uno. Prometió Dios a los creyentes en él y en Mahoma, su fiel Profeta, y a los que cumplen los mandatos de su Ley, el paraíso, es decir, el jardín de las delicias, regado por aguas corrientes, en donde tendrán sede perpetua. La sombra de los árboles les protegerá, sin verse afligidos por el frío o el calor. Se alimentarán de toda clase de frutos, de comida. Lo que a cada uno el apetito le sugiera, lo encontrará delante de sí al instante. Vestirán multicolores vestidos de seda. Se sentarán a la mesa entre placeres, y, ángeles, haciendo las veces de coperos pasearán entre ellos con copas áureas y plateadas, ofreciendo leche en las áureas y vino en las plateadas, y diciendo: Comed y bebed llenos de alegría, Dios ha cumplido lo que prometió. Se unirán a vírgenes, que ni el contacto humano o demoníaco violó, más brillantes ${ }^{3}$ en su belleza que el esplendor del jacinto y del coral. Estos bienes se concederán a los creyentes. A los que no creen, sin embargo, en el verdadero Dios y en el Profeta Mahoma, tendrán el castigo infernal $\sin$ fin. Aunque uno esté abrumado por el peso de muchos pecados, si el día de su muerte creyese en Dios y en Mahoma se verá salvado en el día del juicio por la intervención de Mahoma. Estas y otras muchas cosas, que sería largo enumerar, puesto que ya las conoces desde niño escritas y tenidas en la máxima celebración por todos los sarracenos, ¿Por qué has seguido a la religión cristiana y no a la musulmana, si has de gozar de una mejor vida presente e igualmente la futura?

PEDRO: Aunque el desarrollo de tu discurso, que tiene mucho decoro y dulzura, entre aquellos que piensan que el mayor bien es el goce corporal, pueda atraer una benevolencia no menor como si el mismo Mahoma estuviera presente, sin embargo se me hace raro que esperes esto de mí, que insistas para persuadirme esto, en lo cual en modo alguno podías creer que yo pudiera ser engañado. Cierto es que no me es desconocido quién ha sido Mahoma, como se ha formado como Profeta con una astuta ficción, y para maquinar esto quién se manifestó su consejero. Una cosa sola, creo yo, te queda insegura: Hasta que punto yo juzgue vano e inútil eso que llaman doctrina de Mahoma. Mientras, al contar mi relato, escuches su vida y costumbres, entonces tu podrás distinguir hasta que punto yo sé o no sé lo que es verdadero de aquello.

MOISES: Deseo escuchar eso de ti con avidez

PEDRO: Mahoma huérfano de padre y madre, bajo el patrocinio de su tío-abuelo materno Panefo, pasaba los años de su niñez, sirviendo por aquella época al culto de los ídolos con todos los árabes, como él mismo atestigua en su Corán, diciendo que Dios le había comunicado: fuiste huérfano, y te acepté, estuviste en el error y te dirigí, fuiste pobre, y te enriquecí. Después de unos cuantos años, sirviendo en casa de Cadigia, una viuda muy noble, obtuvo en poco tiempo hasta tal punto obtuvo el favor de su señora que por el derecho conyugal se adueñó de todas las cosas y de la dueña de las cosas también. Con las riquezas de aquélla se hizo muy rico llegando a tal soberbia mental que prometía que el reino árabe debía corresponderle a él si no es porque temía a sus compañeros de tribu, porque no lo tendrían por rey, dado que habían sido iguales y superiores a él. Pero pensando el modo cómo podría hacerse rey, quiso figurarse Profeta, confiado en la gracia de su elocuencia que había adoptado en diversas naciones con la presteza de su ingenio, mientras se esforzaba en la negociación, y contando que en aquél tiempo la mayor parte eran soldados y agricultores, y casi todos idólatras, excepto aquéllos que mantenían heréticamente la Ley de Moisés conforme a los samaritanos y otros cristianos que eran nestorianos y jacobitas. Los jacobitas son herejes así llamados por un tal 
Jacobo, que predican la circuncisión, que creen en Cristo no dios sino sólo hombre justo concebido por el Espíritu Santo y nacido de una virgen, no crucificado ni muerto. En aquel tiempo, en la región de Antioquía, existió un archidiácono, amigo de Mahoma, y éste jacobita por lo que fue llamado al Concilio y condenado. Entristecido por la vergüenza de esta condena, huyó de la región y llegó adonde Mahoma. Mahoma se apoyó en su consejo y lo que pensaba hacer y no podía cumplir por sí mismo lo ejecutó con él. Hubo también dos judíos de aqué$1 \operatorname{los}^{4}$ herejes de Arabia de los que mencionamos antes, llamados Abdías y Cahbalahabar, precisamente éstos se unieron a Mahoma y le prestaron su ayuda para completar sus necios planes. Y estos tres, cada uno conforme a su herejía, mezclaron de modo proporcionado la Ley de Mahoma y dijeron que él decía tales cosas de parte de Dios, las cuales tanto los judíos herejes como los cristianos herejes, que estaban en Arabia, creyeron que eran verdad; quienes se negaron a creer espontáneamente creyeron por la fuerza y el temor de la espada. Ciertamente ninguna otra profecía ni milagro alguno conocemos de él, como hemos escuchado de Moisés, Josué, Samuel, Elías y Eliseo, de los que hemos leído que hicieron muchos milagros.

MOISES: Creemos en la mayoría de los Profetas, de los que no leemos ningún milagro, como Jeremías, Abdías, Amós, Oseas y otros.

PEDRO: Por esto en ellos no se han de buscar milagros, porque no introdujeron novedad alguna de la Ley, ni contradijeron la doctrina mosaica y sabemos que lo que predijeron,en parte, se ha cumplido.

MOISES: No hay duda que los Patriarcas Noé y Abrahám nos han dado nuevos mandamientos por inspiración divina, como de los sacrificios, de la carne que ha de comerse, de la circuncisión y de otros ritos ¿Por qué sin la luz de los milagros su fe se ha presentado para el futuro?

PEDRO: Por esto se cree sinceramente en ellos, porque atestigua que existen ese Profeta, de cuyo testimonio nadie duda, es decir, Moisés. Mahoma, pues, ¿cómo ha de ser recibido como tal entre los Profetas, si a ninguno de los Profetas puede compararse con toda probabilidad?

MOISES: ¿Por qué dices que con ninguna probabilidad se demuestra que es Profeta, de quien, con mucha frecuencia, has oído que se le designa por los milagros?, ¿Es que Duregel, un buey, un animal irracional, no le designó Profeta? Acaso la luna, ingresando por ambas mangas saliendo reintegrada de su seno no le designó Profeta maravilloso? Acaso no fue para dar a conocer esto que la ubre de una oveja, ordeñada de su mano, dio leche para todo el pueblo? Admirable fue que cuando llamó a la higuera para que acudiera donde estaba él, ciertamente el árbol se le acercó y él comió de su fruto, y que la espalda de la oveja, que estaba envenenada para él, colocada en una bandeja habló con él diciéndole: «No comas, que estoy envenenada».

PEDRO: Frívolo es lo que describes. Ni se prueba a juicio de todos vosotros con una mínima garantía, especialmente cuando el mismo Mahoma en su Corán nada semejante relató, sino más bien que lo que no se había escrito de él en el Corán, prohibió creerlo como de verdad. De todos los Profetas ${ }^{5}$, dice, muchos han mentido mucho, lo que, para que no me suceda, sólo esto se tenga por cierto de mí, lo que se comprueba apoyado en la autoridad del Corán. El cual queriendo demostrar por qué no hacía milagros, contó que Dios le había hablado, y así dijo: «Me dijo el Señor: Por esto no te permito hacer milagros porque temo que se te contradiga como a los otros Profetas». Así pues con su propio testimonio se demuestra que él no había hecho ningún signo de virtud ¿Con qué otros indicios se verifica el verdadero Profeta? Los indicios del verdadero Profeta son la honradez de vida, la presentación de milagros, la firme verdad de todo lo dicho. La bondad de vida en Mahoma era la violencia, con la que se hacía pre- 
dicar como Profeta de Dios por la fuerza, gozando con el hurto y la rapiña, y excitando el fuego del deseo a tal grado que no se avergonzaba de manchar un lecho ajeno con el adulterio como si Dios lo ordenase, según se dice de Zanab hija de Ias y esposa de Zet. «El Señor», dice, «te ordena abandonar a tu esposa Zet». Una vez entregada se unió con ella de inmediato. Hasta que punto era falsa esta profecía lo demostró la desvergüenza de su mujer Iasa, cuando sorprendida en adulterio, como no quería repudiarla, contra el testimonio de muchos, la confirmó como no adúltera con el falso testimonio de Gabriel.

De la potencia de su vicio, es decir de su lujuria, se dice que alababa ${ }^{6}$ a Dios ya que copulaba cuarenta veces más de lo normal, felicitándose porque, por gracia divina, el suave olor y la hermosura de las mujeres le deleitaban muchísimo. Sobre los milagros ya se ha hablado. De las guerras, que decía que las había iniciado porque Dios le había ordenado y prometido la victoria, sus dientes molidos por la guerra, la cara aplastada, la gran matanza y huída de los suyos, muestran cuál era la verdad; esas cosas, si el ángel del Señor le custodiara como dices, no le hubieran sucedido, como leemos de Elías y Eliseo ( $I R e 19)$, a los que Dios siempre libró de sus enemigos; a él si fuese tal como dice, siempre le seguiría la victoria, como a Moisés, Josué y David, a quienes trabando combate por mandato divino siempre les acompañaba la victoria (II Re6; ExI7, Jos I). Si fuese verdadero Profeta, como dices, sabría en el supuesto de entablar combate, si resultaría mal ¿Cómo pues, abandonada mi Ley judía dices que debo seguir la Ley mahometana en vez de la cristiana?

MOISES: Esta razón ciertamente parece verdadera al que ha investigado agudamente.

PEDRO: Lo que antes has dicho que he leído libros, que conozco su lengua, que siempre me he nutrido entre los sarracenos, no por ello conviene que siga su Ley.

MOISES: Porque creía que ella era buena, por ello dije que debías aceptarla.

PEDRO: También dijiste que la raíz de su Ley está construida en el fundamento de una razón inconmovible, de ahí que acudamos al campo de la disputa alterna, a las palabras con palabras, a los mandatos con mandatos, si podemos encontrarla bien fundada.

MOISES: De acuerdo

PEDRO: Lo que dices que Mahoma ordena que se debe orar cinco veces al día, lo hizo así porque quiso, con el consejo de sus sabios, que su Ley lograra un punto medio de los judíos y de los cristianos, no por su honradez ni la ayuda divina. Los judíos conforme a su Ley oran tres veces al día, los cristianos siete, pero él ni tres ni siete sino al orar cinco veces puso una oración intermedia. Lo que alabas que, antes de la oración, purifican las manos, brazos y demás miembros del cuerpo, no pertenece a la oración. Lo que pertenece a la oración es la purificación interna, no externa. La limpieza sobre la ablución de los miembros, perteneció a los adoradores de la estrella Venus, quienes queriendo orarle a ella se comportaban como mujeres. Porque fue nombrado caudillo en el día punto de la estrella, por esto ordenó eso. Manifiestas que en el tiempo de la oración lo pregonan con voz pública, lo que no conviene a la oración, a no ser que no pueda imponer otro signo nuevo. Como dices, ordenó que ayunen durante un mes entero, para que opriman los vicios de la carne, lo que es el inicio de la penitencia, pero, por favor, díme ¿qué ventaja hay en ayunar durante el día, y por la noche comer tres o cuatro veces, disfrutar de las mejores carnes y de excelentes alimentos, y hacer uso de las mujeres? Esto no debilita sino arrecia la carne. Lo que dices que una vez al año van en reconocimiento a la casa de Dios que está en la Meca para reconocimiento,y que allí oran, en la casa que, según dicen, había sido de Adán y Abrahán, esto lo tienen ${ }^{7}$ no con autoridad de fe, sino como un cuento. Antes de predicar la Ley, la casa estaba llena de ídolos, pero, si tú, Moisés, supieras cómo era esa casa, qué secreto escondía allí y por qué fue allí Mahoma, y lo que mandó hacer que se encuentra en la Ley, mucho te admirarías de ello.

6 «alababa» laudasse; landasse PL $601 \mathrm{C} 11$.

7 «tienen» habent; babent PL 602 C 13. 
MOISES: Por favor, explícame lo que dices. Pues aunque que yo te predique esta Ley, desconozco el por qué hizo aquel viaje ${ }^{8}$, y mandó hacer las demás cosas que la Ley ordena.

PEDRO: Con brevedad, sin duda, quería notificártelo, pero ya que me lo pides lo mostraré abiertamente. Los dos hijos de Lot, Amón y Moab, honraban esta casa y adoraban dos ídolos, uno labrado 9 de piedra blanca y el otro de piedra negra. El nombre del de la piedra negra era Mercurio $^{10}$, el de la blanca Jamos. El de la piedra negra fue edificado en honor de Saturno, el de la blanca en honor de Marte. Dos veces al año sus fieles subían para adorarlos, a Marte cuando el sol entra en el primer grado de Aries, porque Aries es el signo de Marte. En su separación, según era costumbre, se lanzaban piedras. A Saturno, cuando el sol entra en el primer grado de Libra, porque Libra es el signo de Saturno. Que ofrecían el incienso, desnudos y con la cabeza rapada, esto, como dije, se celebra hasta hoy día ${ }^{11}$ en la India. Los árabes junto con Amón y Moab adoraban a los ídolos. Pero Mahoma, que apareció mucho después, no pudo arrancar esta antigua costumbre, sino que con un cierto cambio de este uso permitió que dieran un rodeo alrededor de la casa vistiendo túnicas sin costura. Pero para no dar la impresión de que ordenaba sacrificar a los ídolos, construyó una imagen de Saturno en la pared, en un ángulo del templo. Para que no apareciera el rostro, se colocó sólo el dorso hacia el exterior. Envió el otro ídolo de Marte, porque estaba esculpido por todos lados, lo puso bajo tierra y colocó una piedra superpuesta y a los hombres que acuden allí para adorarle, mandó que éstos besaran las piedras, y que con las cabezas rapadas y humilladas lanzaran piedras hacia atrás por entre las piernas, y al humillarse muestran las espaldas, lo cual es un signo de la Ley antigua. Díme, pues, Moisés: ¿Con qué intención ordenó esto si no por lo que digo?

MOISES: Te dije que desconozco la intención, porque en ninguna parte lo he descubierto escrito. Sólo sé que se han de arrojar piedras porque dicen hacer esto para propiciar la huida de los demonios. En sus libros vi escrito que Bomar, uno de los diez compañeros de Mahoma, besando las piedras de la manera habitual dijo así: «A vosotras piedras os digo que sé que no tenéis poder de ayudar ni perjudicar, pero, ya que lo hizo Mahoma, sigo su costumbre».

PEDRO: Lo que has dicho que los demonios huyen al arrojar las piedras, no parece ser una razón lógica porque lo que no se percibe con ningún sentido corpóreo, de ninguna manera puede huir sin dificultad. Los demonios sólo huyen con el nombre divino.

MOISES: Porque he escuchado ${ }^{12}$ a los que dicen haber visto y oído a los demonios, y que les han hablado, me extraña que digas que no los percibes con el sentido corporal.

PEDRO: Aunque un ángel no pueda percibirse pòr el sentido corporal, no obstante resultan visibles a quienes viven, según los decretos divinos. Del mismo modo el diablo aparece visible a sus amigos.

MOISES: Esto quisiera saber: Con qué autoridad, o con qué arte podría verlos o hablar?

PEDRO: ¿Por qué deseas saber lo que apenas te concierne?

MOISES: No para ejecutar sus obras sino para querer sólo su ciencia.

PEDRO: ¿Quieres aprender lo que va a aumentar tu error?

MOISES: Gracias a Dios bien me has corregido, he aprendido el sentido en tus palabras.

PEDRO: Ya se ha dicho bastante volvamos al inicio. Porque Mahoma mandó saquear a los adversarios de Dios, hacerlos esclavos y matarlos hasta que quisieran creer o tributar. Eso no está entre los actos de Dios, ni El mandó a ningún Profeta obligar a nadie a creer, sino que el mismo Mahoma lo mandó por la codicia del dinero y para destruir a sus enemigos. Esto, como sabes, no debe hacerse, no, al contrario, si se quiere convertir a alguien, debe hacerse no con

8 «viaje» iter; inter, PL 602 D4.

9 «labrado» patratum, M 69, 1; paratum, PL 602 D 10.

10 «Mercurio» Mercurius, PL 602 D 11; Merculicius, M69 2. Cfr. Septimus, B.: «Petrus Alfonsi on the Cult at Meccas Speculum 56 (1981) 517-533.

11 «dia» diem; dien, PL 603 A 7.

12 «escuchado» audivi; andivi, PL 603 C 7. 
violencia sino con amor y dulzura, según Mahoma en persona atestigua en el Corán bajo la persona del mismísimo Señor que dice: «Si el Señor tu Dios quisiera, todas las gentes creerían» ¿Por qué obligas a que crean? Porque nadie cree sino por voluntad divina. Y en otro lugar dice: «La verdad de Dios ya os ha llegado. Quien crea, lo haga por sí mismo; quien yerre, lo haga por sí mismo, no soy un mozo de cuerda para vosotros». Sigue a Dios, dice, porque se te revela, y espera hasta que Dios juzgue, que es juez de todos. Lo mismo en idéntico lugar, dice: el Señor tu Dios, si quisiera, os colocaría a todos juntos sin discordia bajo una misma Ley. En otro lugar imagina lo mismo, como si Dios le hablara. No debe haber, dice, violencia en la Ley, la verdad y la justicia aparece, quien quiera, que crea por su propia voluntad. Lo mismo en el Corán, no rezo lo que vosotros, incrédulos, rezáis, ni rezáis a quien yo rezo, ni adoro a quien adoráis, yo tengo una Ley, vosotros tenéis una Ley diferente. Y en otro lugar dice: no disputéis con gente de otra Ley si no con palabras delicadas. ¿Por qué mandó saquear, hacer cautiva y obligar a la gente a creer, y confiesa que todo esto es una senda divina? Díme, Moisés, ¿Por qué mandas creer una Ley que está en contradicción consigo misma?

MOISES: El libro del Corán es tal que lo que viene en segundo lugar destruye el primer orden.

PEDRO: El Corán no fue escrito por mano de Mahoma, de ser así, habría sido ordenado. Después de su muerte, los amigos que habían permanecido con él, cada uno, como diré, aportando su lección, compusieron el Corán. Por lo que no sabemos qué orden fue anterior o posterior. Así pues Mahoma mandó saquear, hacer cautivo y matar a gente, porque los Arabes que permanecían en el desierto desconociendo a Dios, para que se deleitaran con sus saqueos y más fácilmente creyeran.

MOISES: Pienso que es verdad lo que dices

PEDRO: Lo que dices que tienen total libertad para alimentarse de toda clase de carne, excepto la carne y sangre de cerdo y animales muertos, también nosotros tenemos plena libertad. Tan sólo en esto diferimos en la carne de cerdo. Esto lo hizo Mahoma para que nosotros los cristianos nos diferenciemos de su Ley. Lo que has dicho sobre las mujeres que se les permite tener a cuatro y que si se repudia a una se puede tomar a otra, esto no se ordena por ningún motivo, pues ni siquiera es preceptivo tomar esposa, a no ser para proquear hijos (Lv18). Y que puedan tener cuantas mujeres compradas o esclavas quieran, sencillamente para nosotros esto es adulterio, porque muchas veces el padre compra alguna estuprada por el hijo, o, por el contrario, el hijo o el hermano compran a una que ha sido corrompida por el padre.

MOISES: En tus palabras se advierte la verdad. Como entre estos preceptos había tal divergencia, ¿por qué Mahoma, que parece tan sabio, mandó que tuvieran lugar?

PEDRO: Mahoma amaba mucho a las mujeres y era en exceso lujurioso y como él mismo confesó, tenía la fuerza viril de cuarenta hombres. Y sobre todo porque los árabes eran muy lujuriosos, satisfizo a la voluntad para que creyeran. Sobre lo que has dicho que tienen mujeres cosanguíneas, era costumbre general en aquélla época, para fomentar entre ellos el vínculo de la amistad. De los juicios que hablaste antes, en algunos puntos están de acuerdo con la Ley de Moisés, en otros disienten, porque Mahoma hizo que su Ley fuera un poco distinta de la Ley de Moisés. Se les manda abstenerse siempre del vino para que unos compañeros embriagados no arruinaran al pueblo. Lo que pregonaste sobre el paraíso se ha de omitir porque no puede comprobarse racionalmente. Ya que el hombre, al separarse el alma del cuerpo y al separarse también los cuatro elementos, no puede servirse de estas cosas seculares lo mismo que antes, lo cual condenamos antes en el título tercero, al hablar de la resurrección de los muertos. El sabio no cree en tal paraíso ni se deja engañar por palabras parecidas. Pero los hombres del tiempo de Mahoma, sin Ley, sin escritura, ignorantes de todo bien, salvo la milicia y el arado, apeteciendo la lujuria, entregados a la gula, podían ser convencidos con facilidad conforme a su deseo. Si se hiciera de otro modo, no los atraería a su Ley.

MOISES: Sin la ayuda de Dios tal y $\tan ^{13}$ grande multitud de gente no creería en él. 
PEDRO: Si con la ayuda de Dios se hubiera conseguido todo, no habría sido vencido muchas veces, ni, como hemos dicho ya, habrían rechinado sus dientes en la guerra, quien, como los demás reyes, era vencido y algunas veces vencía. Pero después de su muerte todos quisieron separarse de su Ley. Había dicho que su cuerpo al tercer día sería llevado al cielo. Cuando comprendieron que él había mentido y vieron que el cadáver hedía, la mayor parte se separó del cuerpo insepulto. Pero Ali ${ }^{14}$, hijo de Labitar uno de los diez compañeros de Mahoma, alcanzó después de su muerte el poder. Quien predicó amablemente, amonestó sagazmente a la gente a creer y dijo que no comprendían bien el lenguaje de Mahoma. Mahoma, afirma, no dijo que antes de la sepultura sería elevado al cielo a la vista de todos. Ciertamente dijo que después de la sepultura del cuerpo, los ángeles, sin saberlo nadie, lo llevarían al cielo, de ahí como no lo enterraran al punto, comenzó a heder para que sepultado al instante. Con esta razón mantuvo a la gente momentáneamente en el error antiguo. Dos hermanos, hijos ${ }^{15}$ del escriba $^{16}$ de Mahoma, Hazán y Hozaín, mortificando fuertemente sus cuerpos con ayunos y vigilias, llegaron casi a la muerte. El padre amonestaba con frecuencia a sus hijos para que no fatigaran sus cuerpos con tan larga mortificación. Y éste viendo que eran necios y que por una mortificación excesiva habían llegado ya a las puertas de la muerte, descubrió la verdad acerca de Mahoma. Conociendo ellos por su padre la maldad de Mahoma, comenzaron a comer y a beber vino, y, así como antes, observaban firmemente su Ley, así finalmente, aunque no del todo, comenzaron a abandonarla, pero algunas gentes los siguieron en su práctica. De todos modos, Moisés, podemos conocer que ni es verdadero Profeta ni lo dicho por él había de verificarse. Aunque omitamos muchas cosas que podemos decir de él, sin embargo mencionaremos una cosa que nosotros y vosotros creemos: El niega a Cristo, al cual creemos muerto y crucificado. Pues él dice: no mataron ni crucificaron a Cristo sino que les pareció. No sólo lo encontrarás en esto mentiroso, sino que vuelve a leer todos los libros y dichos proféticos y encontrarás que miente en todo lo que ha dicho sobre ellos ¿Cómo me exhortas, pues, a que yo crea en un hombre mentiroso si lo encuentras falaz en todo? Suplico la piedad de Dios todopoderoso para que me libre de su error y me haga cumplir la Ley que adopté. Amén.

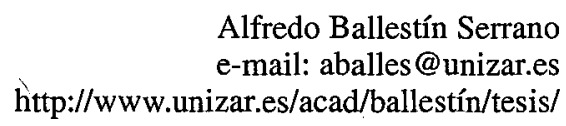

